\title{
Mutation in NRAS in familial Noonan syndrome - Corosuant case report and review of the literature
}

\author{
Sara Ekvall', Maria Wilbe ${ }^{1}$, Jovanna Dahlgren² ${ }^{1}$ Eric Legius ${ }^{3}$, Arie van Haeringen ${ }^{4}$, Otto Westphal ${ }^{2}$, Göran Annerén ${ }^{1}$ \\ and Marie-Louise Bondeson ${ }^{1 *}$
}

\begin{abstract}
Background: Noonan syndrome (NS), a heterogeneous developmental disorder associated with variable clinical expression including short stature, congenital heart defect, unusual pectus deformity and typical facial features, is caused by activating mutations in genes involved in the RAS-MAPK signaling pathway.

Case presentation: Here, we present a clinical and molecular characterization of a small family with Noonan syndrome. Comprehensive mutation analysis of NF1, PTPN11, SOS1, CBL, BRAF, RAF1, SHOC2, MAP2K2, MAP2K1, SPRED1, NRAS, HRAS and KRAS was performed using targeted next-generation sequencing. The result revealed a recurrent mutation in NRAS, c.179G > A (p.G60E), in the index patient. This mutation was inherited from the index patient's father, who also showed signs of NS.

Conclusions: We describe clinical features in this family and review the literature for genotype-phenotype correlations for NS patients with mutations in NRAS. Neither of affected individuals in this family presented with juvenile myelomonocytic leukemia (JMML), which together with previously published results suggest that the risk for NS individuals with a germline NRAS mutation developing JMML is not different from the proportion seen in other NS cases. Interestingly, $50 \%$ of NS individuals with an NRAS mutation (including our family) present with lentigines and/or Café-au-lait spots. This demonstrates a predisposition to hyperpigmented lesions in NRAS-positive NS individuals. In addition, the affected father in our family presented with a hearing deficit since birth, which together with lentigines are two characteristics of NS with multiple lentigines (previously LEOPARD syndrome), supporting the difficulties in diagnosing individuals with RASopathies correctly. The clinical and genetic heterogeneity observed in RASopathies is a challenge for genetic testing. However, next-generation sequencing technology, which allows screening of a large number of genes simultaneously, will facilitate an early and accurate diagnosis of patients with RASopathies.
\end{abstract}

Keywords: NRAS, Noonan syndrome, Mutation, RAS-MAPK pathway, RASopathies

\section{Background}

Noonan syndrome (NS, OMIM 163950) is a relatively common developmental disorder belonging to the RASopathies, a group of clinically and genetically related syndromes $[1,2]$. The molecular cause underlying RASopathies is dysregulation of the RAS-MAPK pathway and 15 different genes affecting this pathway have been associated to RASopathies. Of these 15 genes, eleven have been found to be involved in NS or NS-like conditions, where mutations in PTPN11 are the cause of $\sim 50 \%$ of the cases. The other genes are SOS1 [3, 4], CBL

\footnotetext{
* Correspondence: marielouise.bondeson@igp.uu.se

'Department of Immunology, Genetics and Pathology, Science for Life Laboratory, Uppsala University, Dag Hammarskjölds väg 2075185 Uppsala, Sweden Full list of author information is available at the end of the article
}

[5-7], BRAF [8], RAF1 [9, 10], SHOC2 [11], MAP2K1 [12], RIT1 [13], NRAS [14], KRAS [15, 16] and RRAS [17].

The main characteristics of NS are short stature, congenital heart defect, unusual pectus deformity and typical facial features, such as hypertelorism, ptosis, down-slanting palpebral fissures, low-set posteriorly rotated ears and a broad forehead. However, NS is a clinically variable disorder and additional associated features often present include neonatal failure to thrive, mild mental retardation, various skin manifestations, bleeding abnormalities and multiple skeletal defects $[18,19]$.

$N R A S$ is a four-exon gene, encoding the widely expressed small GTPase NRAS, which act as a membraneassociated molecular switch in the RAS-MAPK pathway [14]. To date, only eight unrelated individuals with NS and 
three NS families have been identified with mutations in NRAS [14, 20-23].

Here, we performed a comprehensive molecular analysis of 13 RASopathy-associated genes; NF1, PTPN11, SOS1, CBL, BRAF, RAF1, SHOC2, MAP2K2, MAP2K1, SPRED1, NRAS, HRAS and KRAS, in a family with NS, which revealed a previously reported mutation in NRAS, c.179G > A (p.G60E). We describe clinical features in this family and review the literature for genotypephenotype correlations for NS patients with mutations in NRAS.

\section{Case presentation}

Clinical investigations and genetic analyses were performed according to the guidelines in the Declaration of Helsinki and approved by the ethical committee of Uppsala University and Gothenburg University, Sweden.
Informed consent was obtained from all patients and specific permission was given for photographs.

\section{Case 1}

This is a 28-year-old woman, who got the clinical diagnosis of Noonan syndrome (NS) at the age of 4 years because of growth retardation, cardiomyopathy and facial features. She is the only child of non-related parents. The father (Case 2) has facial features of NS, but few additional clinical symptoms. She was born to a mother with diabetes during pregnancy with a birth weight of $4.7 \mathrm{~kg}(+3 \mathrm{SDS})$, a length of $52 \mathrm{~cm}(+1$ SDS) and a head circumference of +2 SDS. She also had a large left ventricle, and a systolic murmur, but this disappeared at the age of six years. Postnatally, her growth decelerated and she had feeding difficulties. At 6.5 years of age, her height was $104 \mathrm{~cm}(-2$ SDS) and her weight $18.5 \mathrm{~kg}(-2$ SDS).
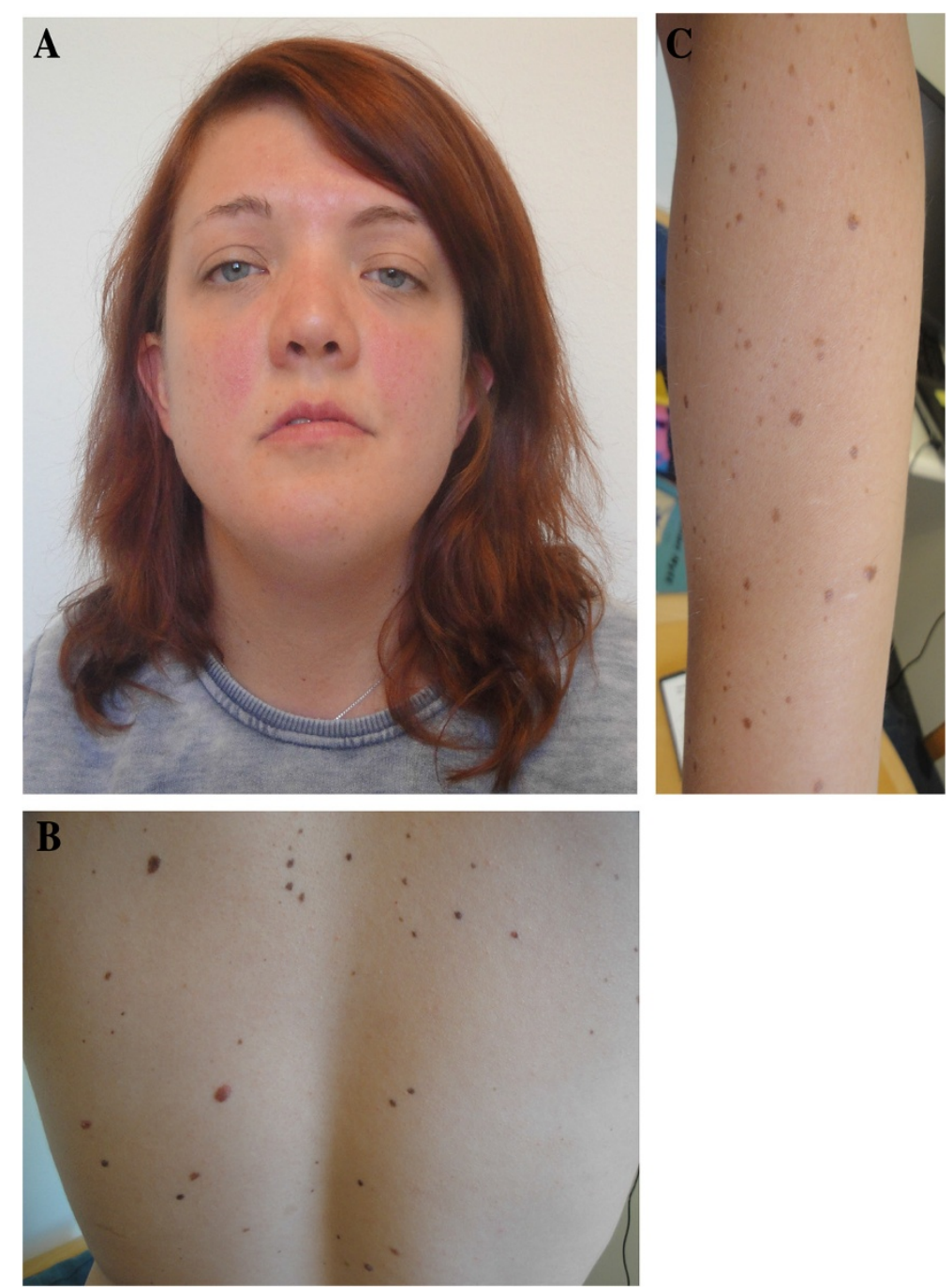

Fig. 1 Photograph of the index patient affected by NS with a mutation in NRAS, p.G60E. a Facial features. b The back with multiple lentigines. c The left arm with multiple lentigines 
She had low endogenous growth hormone (GH) secretion defined as "partial GH deficiency", and started GH therapy within a formal clinical trial (NovoNordisk) from 6.5 years of age. She was treated with GH (dose of $66 \mu \mathrm{g} / \mathrm{kg} /$ day) and responded exceptionally well and treatment was discontinued after two years. However, at 10 years of age, she had her first pubertal signs and GH-treatment was started again using a standard dose of $33 \mu \mathrm{g} / \mathrm{kg} /$ day. At 12.3 years of age, she had menarche. The GH-treatment continued until final height $(\mathrm{FH})$ was reached at the age of 14 years. Her FH is $164.5 \mathrm{~cm}(-0.45 \mathrm{SDS})$ and weight of $60 \mathrm{~kg}(+0.3$ SDS). Her psychomotor development is normal, but she has slight problems of attention deficit. She attended regular school and works as an assistant nurse. At the age of 24 years, she has the following features of NS (Fig. 1a): a large skull $(62 \mathrm{~cm})$ with a broad forehead, hypertelorism, down slanted palpebral fissures, bilateral ptosis (especially of her left eye), short and broad neck with a low hairline, and low-set ears with broad helices. Her hair is normal.
She has two large Café-au-lait spots on her back and $>50$ freckles (lentigines) all over her body, especially on her back (Fig. 1b) and arms (Fig. 1c).

\section{Case 2}

This is the 62-year-old father of Case 1 . He was clinically diagnosed after Case 1 was diagnosed. He has facial features of NS, but few additional clinical symptoms. Sensorineural hearing impairment was present at birth. His growth pattern was normal, but he had a delayed puberty. His $\mathrm{FH}$ is $175.0 \mathrm{~cm}$ (-0.4 SDS) and weight $75 \mathrm{~kg}( \pm 0$ SDS). The intellectual development was normal. He followed normal school and university education and worked as a librarian until the age of 55 years, when he had to retire because of tinnitus. At the age of 62 years, he has the following features of NS (Fig. 2a-c): slight macrocephaly $(61 \mathrm{~cm},+2 \mathrm{SDS})$, bilateral ptosis, hypertelorism and down-slanting palpebral fissures. He
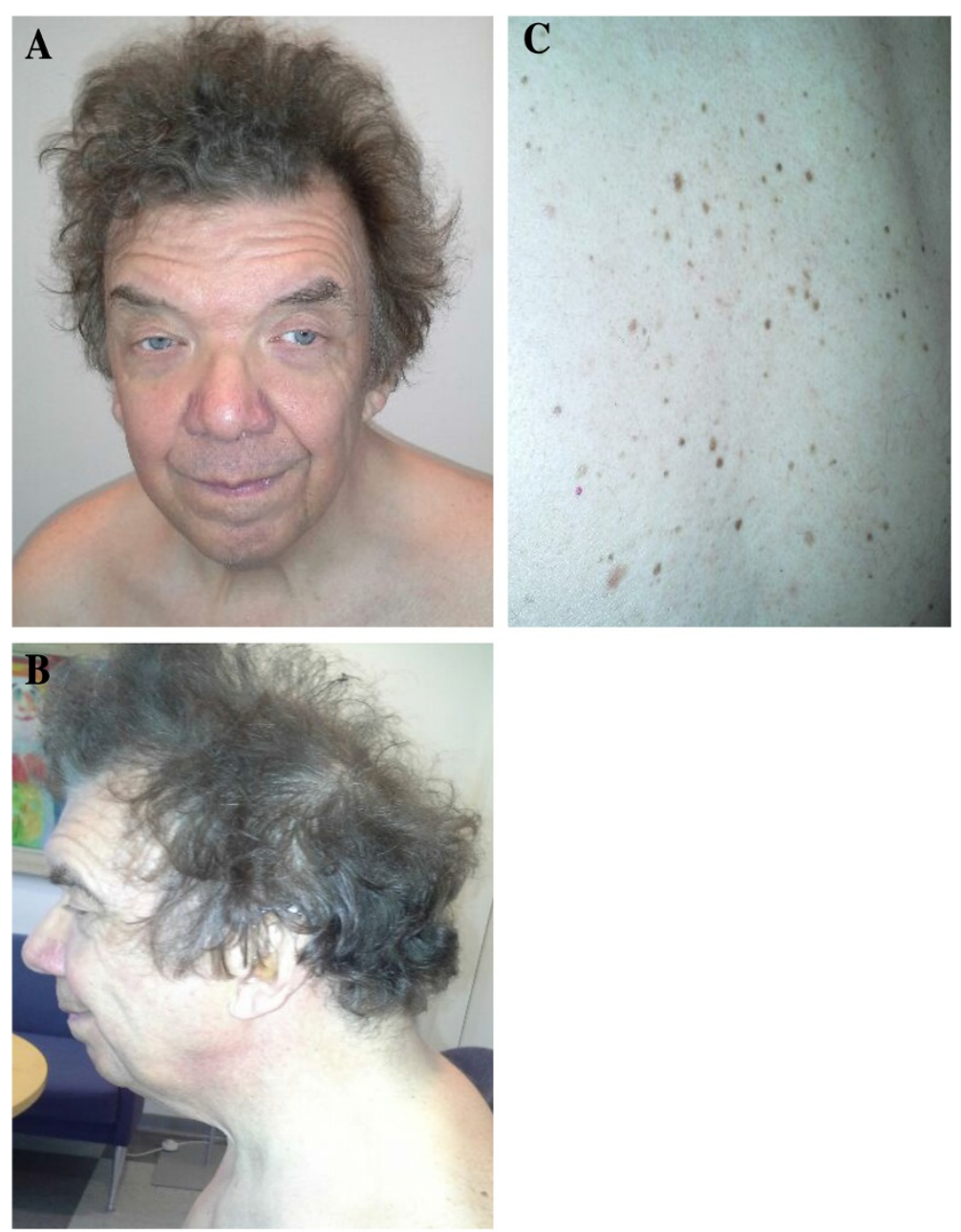

Fig. 2 Photograph of the affected father with the same NRAS mutation, p.G60E. a Frontal facial features. b Additional facial features. c The back with multiple lentigines 
also has curly hair and lentigines on his back. He had a cardiac murmur in childhood that disappeared spontaneously.

\section{Methods}

Genomic DNA from the index patient and her father was extracted from peripheral blood leukocytes according to standard procedures.

\section{Mutation analysis}

The index patient was analyzed for variants in all coding exons and exon-intron boundaries of NF1 (NM_00 0267.3), PTPN11 (NM_002834), SOS1 (NM_005633), CBL (NM_005188), BRAF (NM_004333), RAF1 (NM_00 2880), SHOC2 (NM_007373), MAP2K2 (NM_030662), MAP2K1 (NM_002755), SPRED1 (NM_152594), NRAS (NM_002524), HRAS (NM_005343) and KRAS (NM_00 4985) using Agilent HaloPlex Target Enrichment (Agilent Technologies, Inc., Santa Clara, CA, USA), followed by next-generation sequencing on MiSeq, Illumina (Illumina, Inc., San Diego, CA, USA). Data analysis was performed by NextGENe software v2.3.1 (SoftGenetics, LLC., State College, PA, USA) and BENCHlab NGS (Cartagenia, Inc., Cambridge, MA, USA) [Ekvall et al. Manuscript in preparation].

Variants observed in NRAS exon 2 were verified by bi-directional Sanger sequencing in the index patient and her father. Primer sequences and PCR conditions are available upon request.

\section{Results}

DNA sequencing analysis of the index patient (Fig. 1) was performed on 13 RASopathy-associated genes using HaloPlex target enrichment (Agilent) and nextgeneration sequencing on MiSeq (Illumina). Coverage and read depth of the RASopathy genes in the index patient is shown in Table 1. Targeted bases in region of interest (ROI) with $>30 \mathrm{X}$ read depth was $100 \%$ for all genes, except NF1 (99.8 \%) and SOS1 (99.9 \%). No complementary Sanger sequencing was performed. A heterozygous missense mutation, c.179G $>$ A; p.G60E, in exon 2 of NRAS was identified and verified using Sanger sequencing. This mutation was inherited from the father (Fig. 2), who also shows signs of NS. No additional variants of significance were identified in the index patient.

\section{Conclusions}

To date, only eight unrelated patients with NS and three NS families have been reported positive for NRAS mutations (p.G13D, p.I24N, p.P24L, p.T50I and p.G60E) $[14,20-23]$. In this study, we describe an additional family with NS, where the index patient and her father have c.179G > A (p.G60E). This mutation has been identified in both sporadic and familial NS patients of European
Table 1 Average read depth and coverage of RASopathyassociated genes in this study

\begin{tabular}{llllll}
\hline Gene & $\begin{array}{l}\text { Reference } \\
\text { sequence }\end{array}$ & $\begin{array}{l}\text { ROI }^{\mathrm{a}} \\
\text { bases }\end{array}$ & Exons & $\begin{array}{l}\text { Average } \\
\text { read depth }\end{array}$ & $\begin{array}{l}\text { Coverage } \\
>30 \times(\%)\end{array}$ \\
\hline BRAF & NM_004333 & 3021 & 18 & 12637 & 100.0 \\
CBL & NM_005188 & 3361 & 16 & 12016 & 100.0 \\
HRAS & NM_005343 & 812 & 6 & 14291 & 100.0 \\
KRAS & NM_004985 & 768 & 5 & 10811 & 100.0 \\
MAP2K1 & NM_002755 & 1622 & 11 & 12525 & 100.0 \\
MAP2K2 & NM_030662 & 1643 & 11 & 11127 & 100.0 \\
NF1 & NM_000267 & 10737 & 58 & 12728 & 99.8 \\
NRAS & NM_002524 & 861 & 7 & 16378 & 100.0 \\
PTPN11 & NM_002834 & 6521 & 16 & 16262 & 100.0 \\
RAF1 & NM_002880 & 2587 & 16 & 15985 & 100.0 \\
SHOC2 & NM_007373 & 2069 & 8 & 17812 & 100.0 \\
SOS1 & NM_005633 & 4922 & 23 & 13439 & 99.9 \\
SPRED1 & NM_152594 & 1615 & 7 & 10509 & 100.0 \\
\hline
\end{tabular}

${ }^{\mathrm{a}} \mathrm{ROI}$ Region of interest

origin [14, 23] and is the most common germline mutation in NRAS.

NS patients with NRAS mutations often show a relatively mild phenotype of typical Noonan facial features. A comparison of previously reported NRAS-associated NS cases shows that all of the patients present with typical Noonan facial features (14/14) and 11/13 have macrocephaly or relative macrocephaly, but only half of them display congenital heart defects (7/14). All previously reported patients also show short stature. However, in the family reported here the father's height was normal, while the daughter had short stature successfully treated with $\mathrm{GH}$. The majority has pterygium or webbing of the neck (10/12). Thorax deformity (pectus excavatum) occurs in $5 / 14$ patients, while easy bruising is less common (3/14). Half of the males show cryptorchidism (6/10) and ophthalmological problems appear in 4/14 patients. Motor delay is common (9/14 patients) and as previously reported, intellectual development is often mildly delayed (6 patients normal and 8 mildly delayed). Keratosis pilaris/ hyperkeratosis is less common (4/12 patients) and hair abnormalities occur in about half of the patients. Of note, lentigines are observed in six patients, but leukemia/ cancer are rarely seen (1 patient with JMML) (Table 2 ) $[14,20-23]$. Somatic mutations affecting genes in the RAS-MAPK pathway are associated with cancer, and NS and related disorders are known to cause a predisposition to cancer [24]. Somatic mutations in NRAS are involved in the development of hematological malignancies and in a variety of solid tumors (COSMIC database; http://cancer.sanger.ac.uk/). However, germline NRAS mutations differ from most common somatic NRAS mutations associated 
Table 2 Clinical features of patients with Noonan syndrome caused by NRAS mutations

\begin{tabular}{|c|c|c|c|c|c|c|c|c|}
\hline$\#$ & 1 & 2 & 3 & 4 & 5 & 6 & 7 & 8 \\
\hline Patient & $\begin{array}{l}\text { De Filippi et al. } \\
\text { [20] }\end{array}$ & Runtuwene et al. [21] & Denayer et al. [22] & Denayer et al. [22] & Denayer et al. [22] & Cirstea et al. [14] & Cirstea et al. [14] & Cirstea et al. [14] \\
\hline NRAS mutation & p.G13D & p. $124 \mathrm{~N}$ & p. $124 \mathrm{~N}$ & p.P24L & p.T50l & p.T50l & p.T50l & p.G60E \\
\hline Origin of mutation & de novo & de novo & de novo & Inherited & ND & de novo & de novo & de novo \\
\hline Paternal age at conception & ND & 26 years & ND & ND & ND & 50 years & 34 years & 31 years \\
\hline Age at last examination & 3 years & 30 years & 13 years & 19 years & 2.5 years & 14 years & 7 years & 3.3 years \\
\hline Gender & Male & Male & Male & Male & Male & Male & Male & Female \\
\hline Prenatal findings & ND & Polyhydramnios & ND & ND & ND & $\begin{array}{l}\text { Nuchal edema, } \\
\text { Polyhydramnios }\end{array}$ & Polyhydramnios & $\begin{array}{l}\text { Single umbilical } \\
\text { artery }\end{array}$ \\
\hline Congenital heart defect & - & - & - & ND & $\begin{array}{l}\text { Coarctation aortae, } \\
\text { Patent foramen } \\
\text { ovale }\end{array}$ & $\mathrm{HCM}$ & PS & $\begin{array}{l}\text { Mild HCM, Mitral } \\
\text { valve dysplasia, } \\
\text { PS }\end{array}$ \\
\hline Rythm disturbance & ND & - & ND & ND & - & SVES & - & - \\
\hline Typical facial features & + & + & + & + & + & + & + & + \\
\hline Stature & $5-10^{\text {th }}$ centile & Mild short & $<3^{\text {rd }}$ centile & $10^{\text {th }}-25^{\text {th }}$ centile & $10^{\text {th }}-25^{\text {th }}$ centile & $10^{\text {th }}$ centile ${ }^{a}$ & $<3^{\text {rd }}$ centile & $<3^{\text {rd }}$ centile \\
\hline Macrocephaly & Relative & $>90^{\text {th }}$ centile & $>97^{\text {th }}$ centile & ND & $25^{\text {th }}-50^{\text {th }}$ centile & + & Relative & - \\
\hline Pterygium colli/Webbed neck & - & + & ND & ND & + & + & - & + \\
\hline Thorax deformity & - & Pectus excavatum & Pectus excavatum & ND & Pectus excavatum & + & - & Pectus excavatum \\
\hline Easy bruising & - & - & ND & + & ND & - & - & - \\
\hline Cryptorchidism & - & + & + & ND & + & + & + & NA \\
\hline Ophthalmological problems & ND & - & $\begin{array}{l}\text { Strabismus, Bilateral } \\
\text { keratoconus of the } \\
\text { cornea }\end{array}$ & ND & ND & Myopia & - & - \\
\hline Motor delay/Muscular hypotonia & - & Motor delay & Mild & ND & ND & Mild & + & + \\
\hline Mental development & Normal & $\begin{array}{l}\text { Mild learning } \\
\text { difficulties }\end{array}$ & Normal & Learning difficulties & Normal & Normal & Borderline & Speech delay \\
\hline Keratosis pilaris/Hyperkeratosis & ND & - & ND & ND & ND & Severe & - & + \\
\hline Hair abnormalities & - & - & ND & ND & ND & Curly hair & Curly hair & Sparse thin hair \\
\hline Lentigines/Café-au-lait spots & + & Some lentigines & - & - & - & - & - & - \\
\hline Leukemia/Cancer & JMML & - & - & - & - & - & - & - \\
\hline Other & - & Oligospermia & - & $\begin{array}{l}\text { Inadequate visio-spatial } \\
\text { orientation skills, Inguinal } \\
\text { hernia, Delayed pubertal } \\
\text { development }\end{array}$ & - & Pes equinovarus & - & Palpebral ptosis \\
\hline
\end{tabular}


Table 2 Clinical features of patients with Noonan syndrome caused by NRAS mutations (Continued)

\begin{tabular}{|c|c|c|c|c|c|c|}
\hline$\#$ & 9 & $9 M$ & 10 & 11 & 12 & $12 \mathrm{~F}$ \\
\hline Patient & Cirstea et al. [14] & Cirstea et al. [14] & Kraoua et al. [23] & Kraoua et al. [23] & Present study & Present study \\
\hline NRAS mutation & p.G60E & p.G60E & p.G60E & p.G60E & p.G60E & p.G60E \\
\hline Origin of mutation & Inherited & ND & ND (probably inherited) & de novo & Inherited & ND (probably inherited) \\
\hline Paternal age at conception & 47 years & 44 years & 45 years & 47 years & 34 years & ND \\
\hline Age at last examination & 20 years & 50 years & 24 years & 3 months & 28 years & 62 years \\
\hline Gender & Male & Female & Male & Female & Female & Male \\
\hline Prenatal findings & - & - & Polyhydramnios & Pyelectasis & - & - \\
\hline Congenital heart defect & - & - & - & PS & ASD, HCM & Cardiac murmur \\
\hline Rythm disturbance & - & - & - & - & - & - \\
\hline Typical facial features & + & + & + & + & + & + \\
\hline Stature & $>10^{\text {th }}$ centile & $10^{\text {th }}$ centile & $3^{\text {rd }}$ centile & $3^{\text {rd }}-10^{\text {th }}$ centile & $50^{\text {th }}$ centile $\mathrm{a}^{\mathrm{a}}$ & $50^{\text {th }}$ centile \\
\hline Macrocephaly & + & + & Relative & Relative & + & Relative \\
\hline Pterygium colli/Webbed neck & + & + & + & + & + & + \\
\hline Thorax deformity & + & + & Mildly depressed thorax & Pectus excavatum & - & - \\
\hline Easy bruising & - & - & + & ND & + & - \\
\hline Cryptorchidism & + & NA & - & NA & NA & - \\
\hline Ophthalmological problems & - & Myopia & - & - & $\begin{array}{l}\text { Astigmatis, Myopia, } \\
\text { Strabismus }\end{array}$ & - \\
\hline Motor delay/Muscular hypotonia & + & + & Mild & + & - & - \\
\hline Mental development & Normal-borderline & Normal & Speech delay, dyscalculy & NA & ADHD, normal IQ & Normal \\
\hline Keratosis pilaris/Hyperkeratosis & + & + & ND & - & - & - \\
\hline Hair abnormalities & Curly hair & - & - & Curly hair & - & Curly hair \\
\hline Lentigines/Café-au-lait spots & - & - & + & + & + & + \\
\hline Leukemia/Cancer & - & - & - & - & - & - \\
\hline Other & $\begin{array}{l}\text { Ichtyosiform eczema, } \\
\text { Acanthosis nigricans, } \\
\text { Scoliosis }\end{array}$ & Mother of patient 9 & $\begin{array}{l}\text { Palpebral ptosis, Inguinal } \\
\text { hernia, Scoliosis }\end{array}$ & $\begin{array}{l}\text { Palpebral ptosis, } \\
\text { Unilateral pyelectasis }\end{array}$ & - & $\begin{array}{l}\text { Sensory-neural hearing } \\
\text { deficit, Father of patient } 12\end{array}$ \\
\hline
\end{tabular}

ASD atrial septal defect, HCM hypertrophic cardiomyopathy, JMML juvenile myelomonocytic leukemia, NA not applicable, ND not determined, PS pulmonic stenosis, SVES supraventricular extrasystole ${ }^{a}$ Received growth hormone treatment from the age of 8 years, when partial growth hormone deficiency had been noted 
with malignancies and are less activating in dysregulating intracellular signaling [18].

In summary, we report an NS family with a p.G60E in NRAS. Neither of affected individuals presented with JMML. Thus, the proportion of JMML observed in NRAS patients (1/12) is comparable with the observed proportion of JMML in NS in general [25].

Interestingly, half of the patients (including affected individuals in our family) presented with lentigines and/ or Café-au-lait spots, which is high compared to the prevalence of $3 \%$ for lentigines and $10 \%$ for Café-au-lait spots in the general NS population [26]. Multiple nevi, lentigines and/or Café-au-lait spots are also detectable in one-third of NS individuals with a RAF1 mutation and previous studies have demonstrated a higher prevalence of these features in BRAF-positive NS individuals as well. This suggests that NS individuals with a mutation in NRAS, RAF1 or BRAF have a predisposition to hyperpigmented cutaneous lesions [8, 27]. Of note, the father in our family presented with congenital sensorineural hearing impairment, which together with lentigines are two common features in Noonan syndrome with multiple lentigines (NS-ML, previously LEOPARD syndrome). This demonstrates the wide spectrum of phenotypes within each syndrome as well as the clinical overlap between RASopathies, which makes diagnosis of NS and related disorders challenging.

However, by using the advent of next-generation sequencing technology, which allow for screening of a large number of genes simultaneously, an early and accurate genetic diagnosis of patients with RASopathies will be facilitated.

\section{Consent}

We have obtained written informed consent from the patients for publication of this case report and accompanying images. A copy of the written consent is available from the Editor of this journal.

\section{Abbreviations \\ NS: Noonan syndrome; MAPK: Mitogen-activated protein kinase; JMML: Juvenile myelomonocytic leukemia; GH: Growth hormone; ROI: Region of interest; COSMIC: Catalogue of somatic mutations in cancer; ASD: Atrial septal defect; HCM: Hypertrophic cardiomyopathy; NA: Not applicable; ND: Not determined; PS: Pulmonic stenosis; SVES: Supraventricular extrasystole.}

\section{Competing interests}

The authors declare that there are no conflicts of interest in connection with this article.

\section{Authors' contributions}

MLB, GA and SE conceived the study and participated in its design. GA, JD, $\mathrm{OW}, \mathrm{EL}$ and $\mathrm{AVH}$ performed clinical examination of the patients. SE, MLB and MW carried out the molecular genetic studies and interpreted the data. SE drafted the manuscript with input from the other co-authors. All authors read and approved the final manuscript.

\section{Acknowledgements}

This study was supported by grants from the Swedish Research Council, the Borgström foundation, the Sävstaholm foundation and foundations at the Medical Faculty of Uppsala University, Sweden. The authors wish to thank the family for participating in this study.

\section{Author details}

'Department of Immunology, Genetics and Pathology, Science for Life Laboratory, Uppsala University, Dag Hammarskjölds väg 2075185 Uppsala, Sweden. ${ }^{2}$ Department of Paediatrics, the Sahlgrenska Academy, Gothenburg University, Gothenburg, Sweden. ${ }^{3}$ Department of Human Genetics, KU Leuven, Leuven, Belgium. ${ }^{4}$ Department of Clinical Genetics, Leiden University Medical Center, Leiden, The Netherlands.

Received: 17 April 2015 Accepted: 30 September 2015

Published online: 14 October 2015

\section{References}

1. Roberts AE, Allanson JE, Tartaglia M, Gelb BD. Noonan syndrome. Lancet. 2013;381(9863):333-42.

2. Tartaglia M, Gelb BD. Disorders of dysregulated signal traffic through the RAS-MAPK pathway: phenotypic spectrum and molecular mechanisms. Ann N Y Acad Sci. 2010;1214:99-121.

3. Roberts AE, Araki T, Swanson KD, Montgomery KT, Schiripo TA, Joshi VA, et al. Germline gain-of-function mutations in SOS1 cause Noonan syndrome. Nat Genet. 2007;39(1):70-4.

4. Tartaglia M, Pennacchio LA, Zhao C, Yadav KK, Fodale V, Sarkozy A, et al. Gain-of-function SOS1 mutations cause a distinctive form of Noonan syndrome. Nat Genet. 2007;39(1):75-9.

5. Martinelli S, Checquolo S, Consoli F, Stellacci E, Rossi C, Silvano M, et al. Loss of CBL E3-ligase activity in B-lineage childhood acute lymphoblastic leukaemia. Br J Haematol. 2012;159(1):115-9.

6. Niemeyer CM, Kang MW, Shin DH, Furlan I, Erlacher M, Bunin NJ, et al. Germline CBL mutations cause developmental abnormalities and predispose to juvenile myelomonocytic leukemia. Nat Genet. 2010;42(9):794-800.

7. Perez B, Mechinaud F, Galambrun C, Ben Romdhane N, Isidor B, Philip N, et al. Germline mutations of the CBL gene define a new genetic syndrome with predisposition to juvenile myelomonocytic leukaemia. J Med Genet. 2010;47(10):686-91.

8. Sarkozy A, Carta C, Moretti S, Zampino G, Digilio MC, Pantaleoni F, et al. Germline BRAF mutations in Noonan, LEOPARD, and cardiofaciocutaneous syndromes: molecular diversity and associated phenotypic spectrum. Hum Mutat. 2009;30(4):695-702.

9. Pandit B, Sarkozy A, Pennacchio LA, Carta C, Oishi K, Martinelli S, et al. Gainof-function RAF1 mutations cause Noonan and LEOPARD syndromes with hypertrophic cardiomyopathy. Nat Genet. 2007:39(8):1007-12

10. Razzaque MA, Nishizawa T, Komoike Y, Yagi H, Furutani M, Amo R, et al. Germline gain-of-function mutations in RAF1 cause Noonan syndrome. Nat Genet. 2007;39(8):1013-7.

11. Cordeddu V, Di Schiavi E, Pennacchio LA, Ma'ayan A, Sarkozy A, Fodale V, et al. Mutation of SHOC2 promotes aberrant protein N-myristoylation and causes Noonan-like syndrome with loose anagen hair. Nat Genet. 2009:41(9):1022-6.

12. Nava C, Hanna N, Michot C, Pereira S, Pouvreau N, Niihori T, et al. Cardiofacio-cutaneous and Noonan syndromes due to mutations in the RAS/ MAPK signalling pathway: genotype-phenotype relationships and overlap with Costello syndrome. J Med Genet. 2007;44(12):763-71.

13. Aoki Y, Niihori T, Banjo T, Okamoto N, Mizuno S, Kurosawa K, et al. Gain-offunction mutations in RIT1 cause Noonan syndrome, a RAS/MAPK pathway syndrome. Am J Hum Genet. 2013;93(1):173-80.

14. Cirstea IC, Kutsche K, Dvorsky R, Gremer L, Carta C, Horn D, et al. A restricted spectrum of NRAS mutations causes Noonan syndrome. Nat Genet. 2010;42(1):27-9.

15. Carta C, Pantaleoni F, Bocchinfuso G, Stella L, Vasta I, Sarkozy A, et al. Germline missense mutations affecting KRAS Isoform $B$ are associated with a severe Noonan syndrome phenotype. Am J Hum Genet. 2006;79(1):129-35.

16. Schubbert S, Zenker M, Rowe SL, Boll S, Klein C, Bollag G, et al. Germline KRAS mutations cause Noonan syndrome. Nat Genet. 2006;38(3):331-6.

17. Flex E, Jaiswal M, Pantaleoni F, Martinelli S, Strullu M, Fansa EK, et al. Activating mutations in RRAS underlie a phenotype within the RASopathy spectrum and contribute to leukaemogenesis. Hum Mol Genet. 2014;23(16):4315-27 
18. Allanson JE. Noonan syndrome. J Med Genet. 1987:24(1):9-13.

19. van der Burgt I. Noonan syndrome. Orphanet J Rare Dis. 2007;2:4.

20. De Filippi P, Zecca M, Lisini D, Rosti V, Cagioni C, Carlo-Stella C, et al. Germline mutation of the NRAS gene may be responsible for the development of juvenile myelomonocytic leukaemia. Br J Haematol. 2009;147(5):706-9.

21. Runtuwene $V$, van Eekelen M, Overvoorde J, Rehmann H, Yntema HG, Nillesen WM, et al. Noonan syndrome gain-of-function mutations in NRAS cause zebrafish gastrulation defects. Dis Model Mech. 2011:4(3):393-9.

22. Denayer E, Peeters $H$, Sevenants L, Derbent M, Fryns JP, Legius E. NRAS Mutations in Noonan Syndrome. Mol Syndromol. 2012;3(1):34-8.

23. Kraoua $L$, Journel $H$, Bonnet $P$, Amiel J, Pouvreau N, Baumann C, et al. Constitutional NRAS mutations are rare among patients with Noonan syndrome or juvenile myelomonocytic leukemia. Am J Med Genet A. 2012;158A(10):2407-11.

24. Kratz CP, Franke L, Peters $\mathrm{H}$, Kohlschmidt N, Kazmierczak B, Finckh U, et al. Cancer spectrum and frequency among children with Noonan, Costello, and cardio-facio-cutaneous syndromes. Br J Cancer. 2015;112(8):1392-7.

25. Strullu M, Caye A, Lachenaud J, Cassinat B, Gazal S, Fenneteau O, et al. Juvenile myelomonocytic leukaemia and Noonan syndrome. J Med Genet. 2014;51(10):689-97.

26. Noonan Syndrome.[http://www.ncbi.nlm.nih.gov/books/NBK1124/]

27. Tartaglia M, Zampino G, Gelb BD. Noonan syndrome: clinical aspects and molecular pathogenesis. Mol Syndromol. 2010;1(1):2-26.

\section{Submit your next manuscript to BioMed Central and take full advantage of:}

- Convenient online submission

- Thorough peer review

- No space constraints or color figure charges

- Immediate publication on acceptance

- Inclusion in PubMed, CAS, Scopus and Google Scholar

- Research which is freely available for redistribution 